\title{
Dynamic worksheets: visual learning with the guidance of Polya
}

\author{
Zekeriya Karadag \\ Ontario Institute of Studies in Education (OISE) \\ University of Toronto \\ zkaradag@oise.utoronto.ca
}

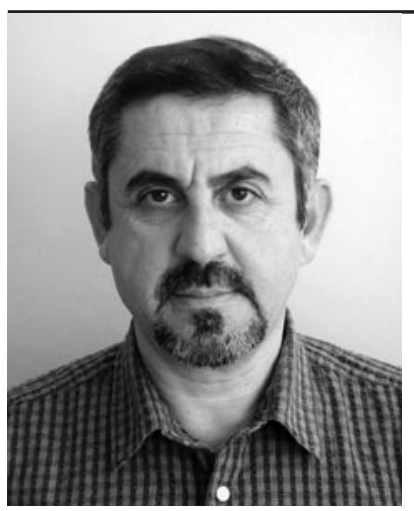

Douglas McDougall

Ontario Institute of Studies

in Education (OISE)

University of Toronto

dmcdougall@oise.utoronto.ca

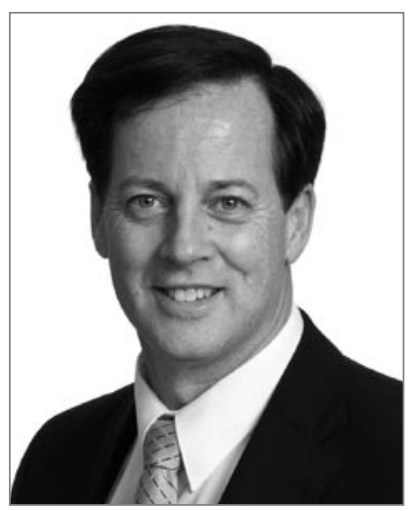

More than sixty years ago, Polya developed a guideline for describing problem solving processes. He suggested four phases of problem solving, such as understanding, devising a plan, carrying out the plan, and looking back [7], which is still applicable to many instances.

We attempt to take a journey with the guidance of his suggestions in a dynamic learning environment, Geogebra. Geogebra is a dynamic learning environment which allows users to create mathematical objects and to interact with these objects. The users of Geogebra, either teachers or students, can use this environment to explain, to explore, and to model mathematical concepts and the relationships between mathematical concepts, or mathematics in general.

We suggest three journey plans with the guidance of Polya's problem solving phases to discuss the ways of using Geogebra (table 1 on the following page). The table provides a tentative outline to use Geogebra as a cognitive tool. The literature suggests two types of use for cognitive tools. The first one is to use cognitive tools to perform time and labour intense procedural tasks and to leave high order thinking responsibility to the user [8]. The other one is to use cognitive tools to extend cognitive abilities for the tasks, which are rather challenging, if not impossible, otherwise [6].

Although the table contains guidelines also to explore and to model mathematics in Geogebra environment, we will focus on the first one and discuss how teachers can use Polya's guideline to explain a mathematical concept, the geometric interpretation of derivative at a point. In this article, we aim to review the use of technology, Geogebra in particular, in the form of the changing nature of teaching and learning. We believe that technology, dynamic and visual learning environments in particular, will affect our perspective to mathematics education not only in terms of teaching and learning strategies but in terms of the content of mathematics education as well. Prior to describing how we suggest using Geogebra, it may be better to review historical evolution of symbolization provided by Moreno-Armella, Hegedus, and Kaput [5]. Their review will help us to develop a unified understanding of cognitive tools.

\section{Evolution of symbolization and cognitive tools}

Cognitive tools allow users to explore mathematical concepts dynamically and have been increasingly discussed in the recent years [2-6]. Luis Moreno-Armella, Stephen J. Hegedus, and James J. Kaput [5] provide an historical overview of symbolization, which can be considered as the evolution of cognitive tools. They identify five stages of the evolution of symbolization "from static, inert inscriptions to dynamic objects or diagrams that are constructible, manipulable and interactive" (p. 103). 


\begin{tabular}{|l|l|l|l|}
\hline & Explaining & Exploring & Modelling \\
\hline Understanding & $\begin{array}{l}\text { Describe the data given } \\
\text { Identify the unknown }\end{array}$ & $\begin{array}{l}\text { Provide worksheet to students } \\
\text { Ask students to explore } \\
\text { the problem } \\
\text { Guide students to identify } \\
\text { the unknown }\end{array}$ & $\begin{array}{l}\text { Provide the theorem to } \\
\text { be modelled } \\
\text { Identify the data given } \\
\text { Describe the unknown }\end{array}$ \\
\hline Devising a plan & $\begin{array}{l}\text { How are the variables } \\
\text { connected to each other } \\
\text { State the strategy }\end{array}$ & $\begin{array}{l}\text { Ask students of the relationships } \\
\text { between variables } \\
\text { Guide students to create } \\
\text { a strategy }\end{array}$ & $\begin{array}{l}\text { Develop mathematical objects } \\
\text { Analyse the relationships } \\
\text { between objects }\end{array}$ \\
\hline Carrying out the plan & $\begin{array}{l}\text { Collect new data to develop } \\
\text { a solution by manipulating } \\
\text { mathematical objects } \\
\text { Ask guiding questions }\end{array}$ & $\begin{array}{l}\text { Guide students to interact } \\
\text { with the mathematical objects } \\
\text { to collect more data } \\
\text { Guide students to identify the } \\
\text { properties of data collected }\end{array}$ & $\begin{array}{l}\text { Manipulate the objects to test } \\
\text { if everything works properly } \\
\text { Create conjectures } \\
\text { Test conjectures }\end{array}$ \\
\hline Looking back & $\begin{array}{l}\text { Repeat the procedure } \\
\text { carried out } \\
\text { Ask what-if questions }\end{array}$ & $\begin{array}{l}\text { Encourage students to alter } \\
\text { the problems } \\
\text { Ask students to create } \\
\text { what-if questions }\end{array}$ & $\begin{array}{l}\text { Alter the variables } \\
\text { Create verbal problems } \\
\text { describing the current case } \\
\text { Pose new problems }\end{array}$ \\
\hline
\end{tabular}

Table 1- Three ways of using Geogebra

The static inert stage of symbolization in mathematics consists of a wide spectrum from ancient writing on bones and parchment to contemporary textbooks and handouts prepared by teachers. In contrast to their hardened and fused inscription with media, the use of chalk and marker pens in the static kinesthetic/aesthetic stage, the second stage, allows users to erase and change the inscription. Besides the flexibility to make changes, they also provide opportunities to use some colours to emphasize particular notations. In the static computational stage, users get a static presentation of the input they provide to some certain devices such as calculators and graphing tools. Gabriel Salomon [8] favours this type of interaction with cognitive tools because he believes that users can have more opportunities to deal with high order thinking tasks if they leave low level cognitive activities to the tools.

The last two stages of this evolution framework focus on the dynamic perspectives of symbolization. In the fourth stage, discrete dynamic stage, a discrete co-action between user and environment is described. The users have more control over the process and the output obtained from the media because they have the ability to change and manipulate the input dynamically. In the fifth stage, continuous dynamic stage, users can get instantaneous and continuous feedback while interacting with the real objects through haptic devices.

The example we will discuss here falls in between fourth and fifth stages. The dynamic worksheets prepared in the Geogebra provide users to create dynamic mathematical objects such as graphs and functions and to interact with these objects. If we assume that these mathematical objects are the real objects of this platform, although the platform itself is virtual in nature, then the continuous interaction between these objects and users could be considered as a continuous dynamic interaction. Similarly, the Geogebra can be considered as a haptic device detecting the movements of the slider and adjustable objects described in this platform.

\section{Geometric interpretation of derivative at a point}

Calculus books usually provide an algebraic definition to describe the geometric meaning of derivative at a point on a specific function. They define a point $P$ on the function $f(x)$, whose coordinates are $(x, f(x))$ and a point $Q$ with the coordinates of $(x+h, f(x+h))$ [1]. Then, they describe the geometric meaning of derivative at the point $A$ as the slope of the secant $P Q$ while the point $Q$ approaches to the point $\mathrm{P}$ or while the value of $\mathrm{h}$ approaches to zero (Fig 1).

Similarly, we created a dynamic worksheet with a function $f(x)$ associated with two points, $A(a, f(a))$ and $B(a+h, f(a+h))$, on it. We defined the coordinates of the points as defined in the calculus books such that the slope of the secant line $A B$ becomes equal to the slope of the tangent line at the point $A$ as the point $B$ approaches to the point A. We also created two sliders to control and manipulate the values of $a$ and $h$ (Fig 2).

\section{Explaining the concept by using the dynamic worksheet}

We present a tentative outline for teachers to explain the geometric interpretation of derivative at a given point $\mathrm{A}$ by using a dynamic worksheet. This outline is guided by the 
Let $\mathrm{P}$ be any point on the graph of a function $y=f(x)$.

Then the coordinates of $\mathrm{P}$ are $\mathrm{P}(x, f(x))$.

Let $\mathrm{Q}$ be a point on the graph near $\mathrm{P}$.

The coordinates of $\mathrm{Q}$ are $\mathrm{Q}(x+h, f(x+h))$, for some small number $h$, positive or negative.

The slope of secant PQ is:

$$
\begin{aligned}
\frac{\Delta y}{\Delta x} & =\frac{f(x+h)-f(x)}{(x+h)-x} \\
\text { or } \frac{\Delta y}{\Delta x} & =\frac{f(x+h)-f(x)}{h}
\end{aligned}
$$

As $h$ gets smaller and smaller, Q moves closer and closer to P, secant PQ comes closer and closer to the tangent at P, and the slope of PQ comes closer and closer to the slope of the tangent. We cannot substitute $h=0$ in equation (1) to determine the slope of the tangent because the result is $\frac{0}{0}$, which is not defined. However, when we know the equation of the function, we can use equation (1) to determine the slope of the tangent at $\mathrm{P}$, when $h$ is very small.

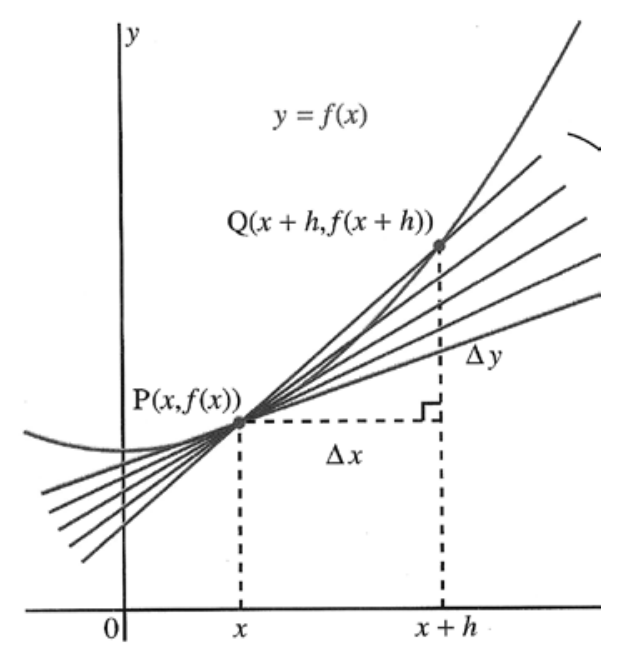

Fig 1 - Definition of derivative in a textbook

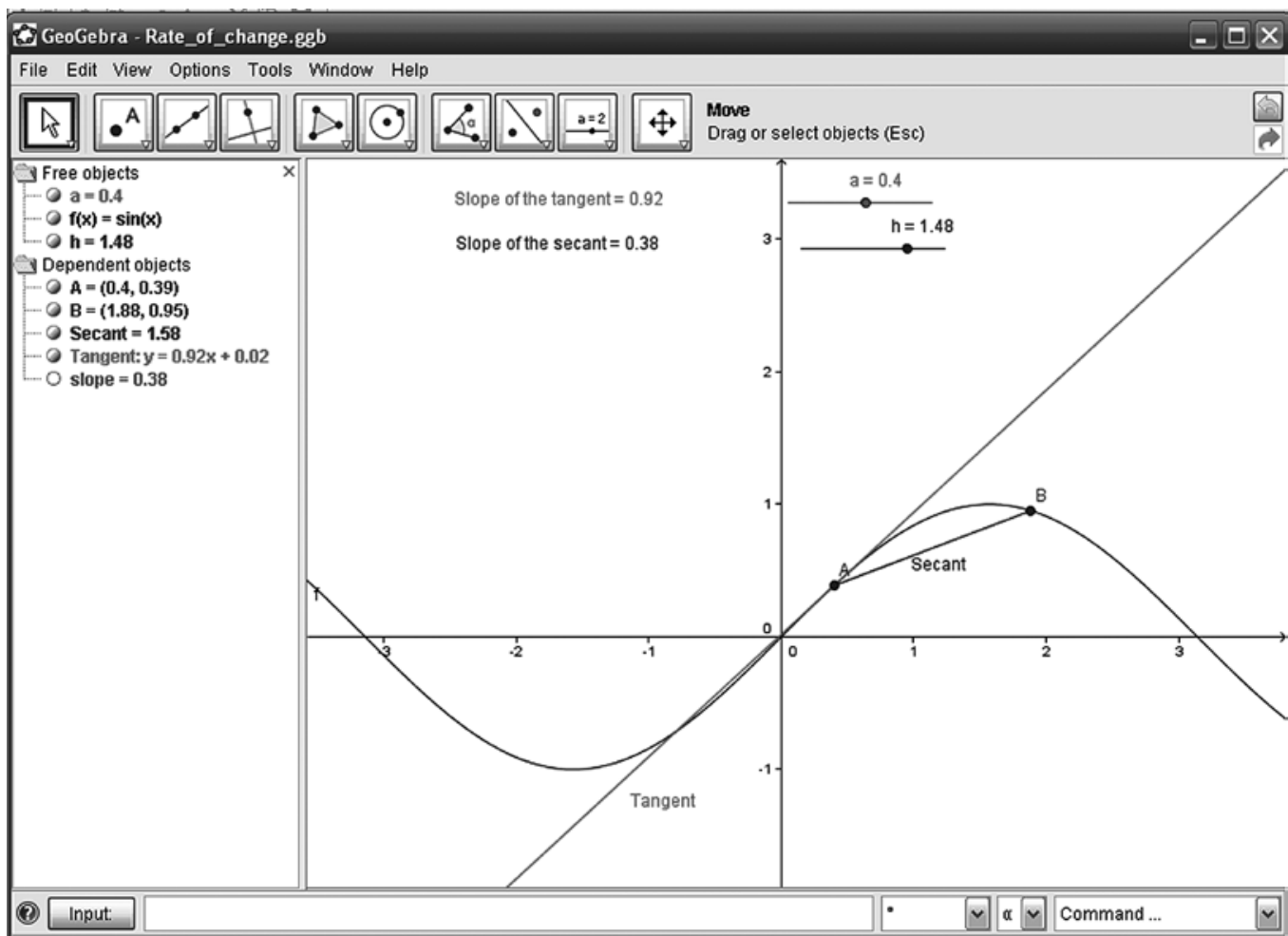

Fig 2 - Definition of derivative in the dynamic worksheet

four phases of George Polya [6]: understanding, devising a plan, carrying out the plan, and looking back.

In the understanding phase, George Polya [6] suggests engaging students to understand the problem completely. Therefore, in this phase, teachers can introduce mathematical objects described in the dynamic worksheet, describe the properties of mathematical objects, and the goal of the problem. Here, the goal is to find the relationship between the slope of the secant line $A B$ and the slope of the tangent line as the point $B$ approaches to the point $A$. The slope of the tangent line can be seen on the algebra window of the Geogebra (Fig 2).

At this moment, it is important to remember that all these mathematical objects created and illustrated in the Geogebra should be considered as data. They will be information when the receivers, students in our case, perceive this data [4]. Similarly, in order to engage students to build their own knowledge, teachers should guide them to receive data as information and to process this information into knowledge.

In the devising a plan phase, teachers can guide students to understand how these mathematical objects are connected to each other. For example, students can be guided to conjecture a relation between two slopes as the slider $\mathrm{h}$ is moved. In addition, they can be engaged to develop conjectures between free objects and dependent objects seen on the algebra window. 


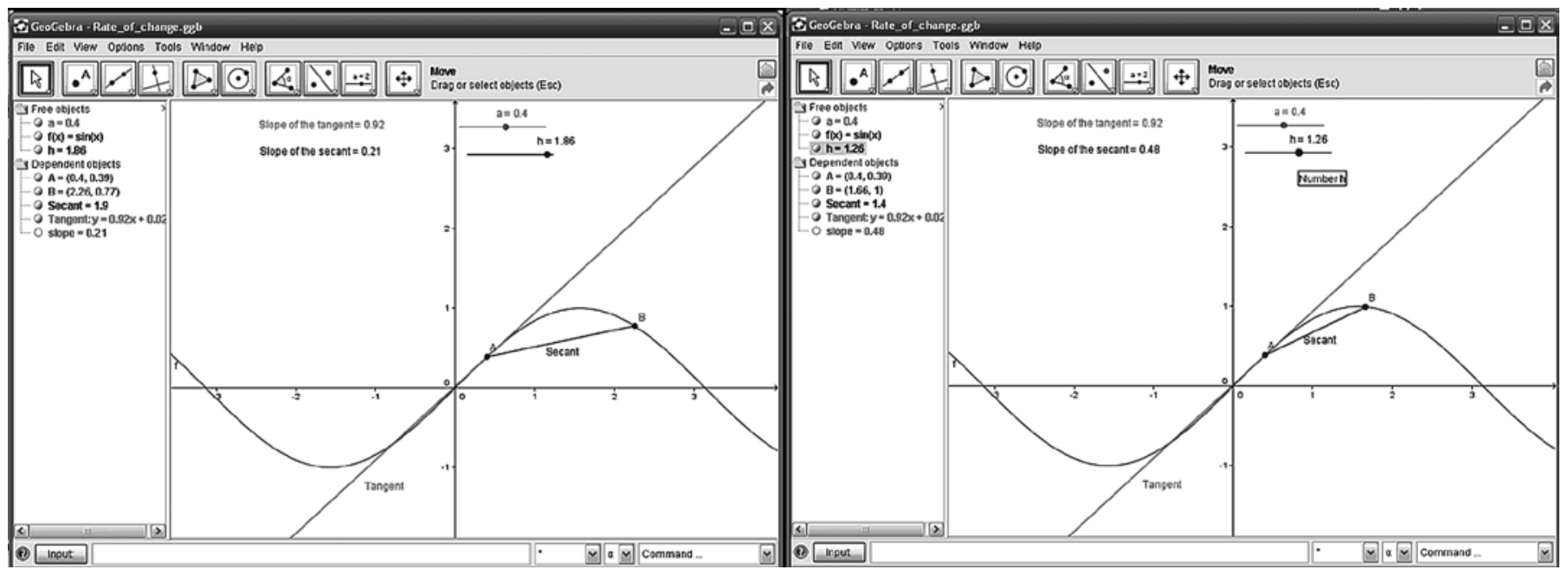

Fig 3 - Different screenshots of the dynamic worksheet obtained through manipulation of the sliders

Once they develop an understanding of mathematical objects and the relationships between them, teachers can move to the carrying out the plan phase to collect more data to test conjectures by manipulating the sliders (Fig 3). Students should develop an understanding of the relation between the slopes by trial and error at this phase. This trial and error, or carrying out the plan, stage should provide students with the opportunities to create cognitive connections between their previous knowledge and the outcomes of the current exploration. They can create these cognitive connections either in this stage or in the next, looking back, stage.

In the last phase, students can be engaged to look back by altering the function and by asking what-if questions:

- What if I change the function?

- What if I play with the slider a?

- What if I move the point B to the left of the point $A$ and approach from the left?

It is quite possible to create more questions by teachers or by students.

\section{Discussion}

As seen in the example illustrated here, teachers can engage their students to visualize mathematical objects and to develop a visual understanding of mathematical concepts and the relations between them. As a result of dynamic and visual interaction between users and the environment, Geogebra, students can experience a new understanding of mathematics, visual understanding as described in the fifth stage of symbolization by Luis Moreno-Armella, Stephen J. Hegedus, and James J. Kaput [4].

Today's students are more familiar with visual learning because they learn many new technologies such as computers, internet, and cell phones visually. It might be very challenging for them to learn algebra symbolically, and they may better understand algebraic notations after they developed a visual understanding of mathematical concepts.
Therefore, the next step for us should be to explore the effects of this new learning type. How do students transfer the outcomes of this dynamic and visual interaction to the algebraic world of mathematics? More importantly, do they really need to transfer these understandings or should they develop an algebraic understanding associated with visual learning?

\section{References}

1. Alexander, Robert, Edwards, Bonnie, Harrison, Peter J., Lenjosek, Antonietta, Rajotte, Linda, and Taylor, Peter (2003) Advanced Functions and Introductory Calculus. Pearson Education Canada.

2. Hoyles, C. and Noss, R. (2008) Next steps in implementing Kaput's research programme. Educational Studies in Mathematics, Vol 68: pp. 85-97.

3. Kaput, James J. (1992) "Technology and mathematics education." In D. A. Grouws, ed. Handbook of Research on Mathematics Teaching and Learning. The National Council of Teacher of Mathematics.

4. Massaro, D. W., \& Cowan, N. (1993) Information processing models: Microscopes of the mind. Annual Review of the Psychology, Vol 44: pp. 383-425.

5. Moreno-Armella, L., Hegedus, S. J., \& Kaput, J. J. (2008). From static to dynamic mathematics: Historical and representational perspectives. Educational Studies in Mathematics, Vol 68: 99-111.

6. Pea, Roy D. (1993) Practices of distributed intelligence and designs for education. In Gabriel Salomon, ed. Distributed cognitions: Psychological and educational considerations. Cambridge University Press.

7. Polya, George. (1973). How to solve it: A new aspect of mathematical method. Princeton University Press.

8. Salomon, Gabriel (1993) "No distribution without individual's cognition: a dynamic interactional view." In Gabriel Salomon, ed. Distributed Cognition: Psychological and Educational Considerations. Cambridge University Press. 